\title{
Study on the period of acceptability of cooked rice
}

\author{
M.A. Ali, S.M.K. Hasan ${ }^{1}$, M.N. Islam and M.N. Islam \\ Department of Food Technology and Rural Industries, Bangladesh Agricultural University, Mymensingh- \\ 2202, Bangladesh and ${ }^{1}$ Department of Food Processing and Preservation, HSTU, Dinajpur
}

\begin{abstract}
The study attempts to determine the period of acceptability of cooked rice (parboiled) of Pajam variety. Cooling studies on cooked rice showed the highest cooling rate in soaked water, and successively followed by refrigeration, under fan air and at room temperature $\left(30 \pm 2^{0} \mathrm{C}\right)$. The moisture, protein, fat, ash and total carbohydrate contents $(\mathrm{wb})$ were $9.68,4.93,0.36,0.32$ and $84.71 \%$ respectively in raw rice; $12.37,8.36,0.40,0.57$ and $78.29 \%$ respectively in parboiled rice and $65.99,3.24,0.15,0.14$ and $30.47 \%$ respectively in cooked rice (parboiled). After 24 hours of storage moisture, protein, fat, ash and carbohydrate contents were $66.47 \%, 5.69 \%, 0.13 \%, 0.14 \%$ and $15.73 \%$ respectively in rice at room temperature; $69.12 \%, 3.64 \%, 0.13 \%, 0.13 \%$ and $26.98 \%$ respectively in refrigerated rice and 64.38 $\%, 3.53 \%, 0.15 \%, 0.15 \%$ and $31.78 \%$ respectively in frozen rice. The cooked rice stored at room temperature for 24 hours showed $4.2 \times 10^{4} \mathrm{cfu} / \mathrm{g}$, and the refrigerated and frozen rice showed no viable load while after another 24 hours of storage the refrigerated rice showed $6.9 \times 10^{5} \mathrm{cfu} / \mathrm{g}$ and frozen rice showed no load. The sensory evaluation revealed the 'cooked rice' and 'refrigerated and reheated rice' were equally acceptable and ranked as 'like very much' in terms of colour, taste, texture and overall acceptability. To ensure the maximum hygienic quality and desirable taste the cooked rice (parboiled) might be kept for a maximum period of 20 hours at room temperature and 48 hours in a refrigerator and reheated by microwave oven for 1 minute before serving to the consumer.
\end{abstract}

Keywords: Period, Acceptability, Cooked rice

\section{Introduction}

Rice (Oryza sativa L., family Gramineae) is the most widely consumed basic foodstuff in the world. In 39 countries rice is the staple diet, but the dependence on rice for food energy is much higher in Asia than in other regions of the world. Rice provides 35 to 59 percent of energy consumed by 2700 million people in Asia (FAO, 1984) and eaten as cooked rice. Cooking is a gelatinization and hydro-thermal process involving with heat and mass transfer. The cooked rice (parboiled) is highly perishable due to its high water activity. It is easily affected by microorganisms which ferment the rice starch under room temperature. Cooked rice is even more easily and dangerously affected by microbes which are responsible for food poisoning and food infection (Frazier, 1995). Recent concern with pathogens in ready to cook or ready to serve food is prompted by the considerable investigation relating to pre-harvest and post-harvest food safety (Hubbert et al., 1996). Now-a-days people find less time to relax and desire to get ready-to-eat foods. Accordingly, an attempt has been made to determine the acceptable cooling methods for cooked rice and to determine the period of acceptability of cooked rice (parboiled) using Pajam rice. Since there are only few references available on cooked rice, it is decided to study the compositional changes of raw, parboiled and cooked (parboiled) rice to observe the nutritional variations due to processing. The purpose of the research work was to establish an acceptable procedure for instant supply of hygienic cooked rice (parboiled) with a desirable taste.

\section{Materials and Methods}

In this study raw, parboiled and cooked rice (parboiled) were used as samples. Brief descriptions of the methods followed for the study are given below: 
Cooking: $1 \mathrm{~kg}$ of parboiled rice was washed thoroughly with tap water and cooked over a plate heater. Complete cooking required about 1.7 liter of water and about 25 minutes of time.

Cooling: The cooked rice was cooled at room temperature $\left(30 \pm 2^{\circ} \mathrm{C}\right)$, under ceiling fan, in refrigerator and in potable water $\left(22 \pm 2^{\circ} \mathrm{C}\right)$ using $3 \mathrm{~cm}, 5 \mathrm{~cm}$ and $7 \mathrm{~cm}$ thick layers. When soaked in water the rice was kept below $2 \mathrm{~cm}$ from the water surface. The cooled rice was kept at room temperature, in refrigerator and in freezer for 24 hours for further studies.

Proximate composition analysis: The moisture, crude protein, crude fat and ash contents of the rice were determined by AOAC (1984) and following the methods as stated by Ranganna (1991). Total carbohydrate content of the samples was determined by subtracting method (Pearson, 1976). The starch content of the samples was determined by direct Acid Hydrolysis method as described by Ranganna (1991).

Total viable count (TVC): The bacterial load in the cooked rice kept at room temperature $\left(30 \pm 2{ }^{\circ} \mathrm{C}\right)$ for 24 hours, and in refrigerator and freezer for 24 and 48 hours, was calculated by the standard Plate Count Method as stated by Ranganna (1991).

Reheating the cooled rice: The cooled rice (kept in refrigerator and freezer for 24 hours) was equilibrated to room temperature and reheated in a microwave oven (at auto scale-1) for 1 minute.

Sensory evaluation: The reheated rice was served to 13 panelists with curry (vegetable plus small indigenous species of fish) and the sensory attributes such as colour, taste, texture and overall acceptability were evaluated as per Hedonic Rating test (Ranganna, 1991).

\section{Results and Discussion}

Cooling the cooked rice: To observe the effect of thickness on cooling rate as influenced by various cooling systems the cooked rice was spread at $3 \mathrm{~cm}, 5 \mathrm{~cm}$ and $7 \mathrm{~cm}$ thick layers. At an average Relative Humidity of 79\% found cooling results has been shown in Table 1 which shows that to reach a specific temperature required time is lower for lower thickness and higher for higher thickness and for a specific thickness the cooling rate may be expressed as follows:

Room temperature < Fan air $<$ Refrigerator $<$ Soaked in water.

This seems to be reasonable from the standpoint of temperature gradient and air flow resistance and negligible external surface resistance (Heldman and Lund, 1992).

Table1. Cooling rate of the cooked rice at various cooling systems

\begin{tabular}{|c|c|c|c|c|c|c|c|c|c|c|c|c|}
\hline \multirow[t]{2}{*}{$\begin{array}{l}\text { Cooling } \\
\text { time (min) }\end{array}$} & \multicolumn{3}{|c|}{$\begin{array}{c}\text { Room Temperature } \\
\left(30 \pm 2^{0} \mathrm{C}\right)\end{array}$} & \multicolumn{3}{|c|}{$\begin{array}{l}\text { Under fan air } \\
\left(30 \pm 2{ }^{\circ} \mathrm{C}\right)\end{array}$} & \multicolumn{3}{|c|}{$\begin{array}{c}\text { Soaked in water } \\
\left(22 \pm 2{ }^{0} \mathrm{C}\right)\end{array}$} & \multicolumn{3}{|c|}{ Refrigerator } \\
\hline & $3 \mathrm{~cm}$ & $5 \mathrm{~cm}$ & $7 \mathrm{~cm}$ & $3 \mathrm{~cm}$ & $5 \mathrm{~cm}$ & $7 \mathrm{~cm}$ & $3 \mathrm{~cm}$ & $5 \mathrm{~cm}$ & $7 \mathrm{~cm}$ & $3 \mathrm{~cm}$ & $5 \mathrm{~cm}$ & $7 \mathrm{~cm}$ \\
\hline 0 & 98 & 98 & 98 & 98 & 98 & 98 & 98 & 98 & 98 & 98 & 98 & 98 \\
\hline 10 & 67 & 68 & 68 & 63 & 67 & 70 & 28 & 30 & 31 & 51 & 58 & 63 \\
\hline 20 & 48 & 51 & 53 & 47 & 50 & 52 & 27 & 26 & 27 & 37 & 46 & 53 \\
\hline 30 & 44 & 48 & 49 & 39 & 40 & 46 & 25 & 26 & 26 & 29 & 39 & 43 \\
\hline 35 & 40 & 44 & 47 & 36 & 37 & 42 & 25 & 25 & 26 & 26 & 32 & 32 \\
\hline 40 & 39 & 40 & 41 & 33 & 35 & 38 & 24 & 25 & 25 & 23 & 25 & 25 \\
\hline 45 & 38 & 39 & 40 & 32 & 33 & 35 & 24 & 24 & 24 & 21 & 22 & 22 \\
\hline 50 & 38 & 38 & 39 & 32 & 32 & 33 & 24 & 24 & 24 & 19 & 20 & 20 \\
\hline 55 & 38 & 38 & 38 & 32 & 32 & 32 & 24 & 24 & 24 & 18 & 19 & 19 \\
\hline
\end{tabular}


As the cooling at room temperature requires the highest time there is a possibility of microbial contamination of the cooked rice. Again cooling in water is dependent on the volume and temperature of the water. If larger volume of water at lower temperature is used the cooling rate would be higher and vice versa. In case of a refrigerated storage, if a larger amount of rice is used immediately after cooking for cooling it would be dangerous and risky due to sudden increase of refrigeration load and the products would not be cooled as expected with resultant loss in quality. Cooling rate under ceiling fan is higher than that of still air at constant temperature and there is a less possibility of microbial contamination. So considering these facts it may be concluded that to protect the cooked rice from the microbial contamination it should be cooled immediately after cooking by spreading in a reasonable thick layer under fan-air before being kept in a refrigerator.

Proximate composition analysis: The proximate composition analyzed for moisture, protein, fat, ash, starch and total carbohydrate contents are presented in Table 2. It shows that the moisture content in raw milled rice (var. Pajam) was $9.68 \%$ (wb) which is approximately similar to that found by McCall et al. (1951) who reported 9.0-12.0\% (wb) moisture in raw rice. The moisture content in parboiled rice was $12.37 \%(\mathrm{wb})$. This result is higher than that found by McCance and Widdowson (1995) who reported $11.4 \%(\mathrm{wb})$ and lower than the result found by Ali et al., (1992) who obtained $13.70 \%$ (wb) moisture in parboiled milled rice. This variation might be due to the difference in initial moisture content in paddy and subsequent storage conditions after milling operations.

Table 2. Nutritional variation of the rice (var. Pajam) due to processing and storage

\begin{tabular}{|l|c|c|c|c|c|c|}
\hline \multirow{2}{*}{ Condition of Rice } & \multicolumn{7}{|c|}{ Compositional } \\
\cline { 2 - 7 } & $\begin{array}{c}\text { \%Moisture } \\
(\mathrm{Wb})\end{array}$ & $\begin{array}{c}\text { \%Protein } \\
(\mathrm{Wb})\end{array}$ & $\begin{array}{c}\text { \%Fat } \\
(\mathrm{Wb})\end{array}$ & $\begin{array}{c}\text { \%Ash } \\
(\mathrm{Wb})\end{array}$ & $\begin{array}{c}\text { \%Starch } \\
(\mathrm{Wb})\end{array}$ & $\begin{array}{c}\text { \%Carbohydrate } \\
(\mathrm{Wb})\end{array}$ \\
\hline Raw & 9.68 & 4.93 & 0.36 & 0.32 & 61.36 & 84.71 \\
\hline Parboiled & 12.37 & 8.36 & 0.40 & 0.57 & 44.11 & 78.29 \\
\hline Immediately Cooked & 65.99 & 3.24 & 0.15 & 0.14 & 15.78 & 30.47 \\
\hline Room temp* & 66.47 & 5.69 & 0.13 & 0.14 & 9.29 & 27.56 \\
\hline Refrigerated* & 69.12 & 3.64 & 0.13 & 0.13 & 13.25 & 26.98 \\
\hline Frozen * & 64.38 & 3.53 & 0.15 & 0.15 & 20.95 & 31.78 \\
\hline
\end{tabular}

'Wb' means the values are given on wet weight basis.

* indicates preserved for 24 hours.

The moisture content in the cooked rice was $65.99 \%$ which indicated that the used parboiled rice absorbed $53-54 \%$ of moisture to be completely cooked. After 24 hours the moisture content of cooked rice (parboiled) kept at room temperature $(66.47 \%)$ and in refrigerator $(69.12 \%)$ was higher and for frozen rice $(64.38 \%)$ the value is lower than that of immediately cooked rice. Immediately after cooking the temperature of rice was much higher and consequently some moisture was evaporated and when kept in refrigerator it absorbed moisture to be in equilibrium with the humidity in the refrigerator, since humidity within the refrigerator was higher than the equilibrium relative humidity of the evaporated rice. Again while kept at room temperature the cooled rice absorbed moisture from the environment and some alcohol was produced by fermentation of starch present in the cooked rice and due to this reason the content might increase. According to Heldman (1977) during freezing, ice crystals are formed in the food products and when heated to room temperature these crystals are melted as well as evaporated and consequently moisture content of the frozen rice decreased. 
The protein content of the raw milled rice (4.93\%) shown in Table 2 is significantly lower than that found by Houston and Kohler (1970) who $6.7 \%(\mathrm{wb})$ protein in raw rice; and for the parboiled rice the value $(8.36 \%)$ is within the range found by Juliano (1972), who reported that protein content of parboiled rice to be in the range of 5.6 to $13.3 \%(\mathrm{wb})$. Protein content in the cooked rice $(3.24 \%)$ is significantly lower than that of parboiled rice which might be due to the increase in moisture content of rice and cooking effect. The protein content of the cooked rice (5.69\%) kept at room temperature for 24 hours is comparatively higher than that of cooked rice which might be due to the growth of microorganisms in the rice according to the concept of Islam et al. (2002), who stated that on an average bacterial body contains about $15 \%$ of protein and carbohydrate is the basic source for microbial growth. The protein content found in the refrigerated (3.64 \%) and frozen rice $(3.53 \%)$ was slightly higher than that of cooked rice which also might be due to the growth of microorganisms because certain psychrotrophic bacteria (e.g., Pediococcus spp., Pseudomonas sp., Flavobacterium sp., Achromobacter sp. and Alcaligenes $s p$.) are able to grow at commercial refrigeration temperatures which are responsible for the loss of quality in nonsterile refrigerated foods (Frazier, 1995). The laboratory experiment showed that storage of cooked rice in refrigerator for 24 hours resulted in growth of some bacteria. Slight increase in protein content in the refrigerated rice might be due to this reason. The increase of protein content in the frozen rice might be due to the decrease in moisture content by formation of ice crystal and evaporation (Heldman, 1977).

Table 2 shows that fat content of the raw rice $(0.36 \%)$ is in the range as found by Grist (1965) who reported 0.30 to $0.40 \%(\mathrm{wb})$ fat in raw milled rice and Juliano (1972) also showed the range to be from 0.30 to $2.7 \%(\mathrm{wb})$. The fat content in the parboiled rice $(0.40$ $\%$ is lower than that found by Houston and Kohler (1970) and similar to that found by Juliano (1972) and those were respectively $1.9 \%(\mathrm{wb})$ and $0.4 \%$. The fat content of cooked rice $(0.15 \%)$ is significantly lower than that of parboiled rice which might be due to the increase of moisture content in the cooked rice and oxidation of fat of the rice. The fat content of cooked rice kept in refrigerator $(0.13 \%)$ and freezer $(0.15 \%)$ for 24 hours is approximately similar to that of cooked rice. It is thus concluded that there is negligible fat loss due to refrigeration and freezing of cooked rice (parboiled). The fat content in the cooked rice $(0.13 \%)$ kept at room temperature for 24 hours is lower than that of parboiled rice and cooked rice, which might be due to the oxidation of the fat present in rice as most of the plant fats are unsaturated fats, being easily oxidized by atmospheric oxygen.

The ash content of raw rice (0.32\%) as shown in Table 2 is similar to that $(0.32 \% \mathrm{wb})$ found by Platt (1939) and Grist (1965) and less than that $(0.4 \% \mathrm{wb})$ found by Kik and Williams (1945) and higher than that $(0.3 \% \mathrm{wb})$ found by Juliano (1972). The ash content in the parboiled rice was $0.57 \%(\mathrm{wb})$ which was higher than those obtained by McCall et al. (1951), Watt and Merrill (1963) who reported $0.45 \%$ and $0.50 \%(\mathrm{wb})$ respectively and approximately similar to that found by Ali et al. (1992) who reported $0.60 \%(\mathrm{wb})$ ash in parboiled rice. The ash content of the cooked rice $(0.14 \%)$ is significantly lower than that of parboiled rice and the ash content for the cooked rice (parboiled) kept at room temperature, in refrigerator and freezer for 24 hours were $0.14 \%, 0.13 \%$ and $0.15 \%(\mathrm{wb})$ respectively. Comparing these values with the ash content of parboiled rice, it is seen that storage conditions do not affect ash content, but cooking process itself results in reduced ash content presumably because of leaching of ash into the cooking water which is subsequently drained out. 
Table 2 shows that starch content in the raw rice (61.36\%) is lower than that of parboiled rice $(44.11 \%)$ which proves that due to boiling the starch content in rice would significantly decrease and the value for the parboiled rice is similar to those found by Simmonds (1980) and Kundu (2006) who reported $44.47 \%$ and $44.75 \%(w b)$ starch in parboiled rice respectively. Starch content in the cooked rice decreased drastically to $15.78 \%$ from $44.11 \%$ (parboiled) due to moisture absorption by the rice and cooking effect. Starch content in the cooked rice kept at room temperature, in refrigerator and freezer for 24 hours was $9.29 \%$, $13.25 \%$ and $20.95 \%$ which indicates that if the cooked rice is kept at room temperature for maximum 24 hours, most of its starch will be lost by fermentation while the rice kept in refrigerator gives higher starch content due to reduced fermentation; and when the rice is kept in freezer, there is no change in starch content of the cooked rice rather it increased probably due to moisture evaporation.

The carbohydrate content of the raw rice ( $84.71 \%)$ is significantly lower than that found by Grist (1965) who reported $91.40 \%(w b)$ carbohydrate in raw rice, and higher than those found by Watt and Merrill (1963) and Houston and Kohler (1970) who mentioned the value $80.40 \%$ and $80.40 \%(\mathrm{wb})$ respectively. The carbohydrate content in parboiled rice $(78.29 \%)$ is approximately similar to those found by Gopalan et al. (1980) and Ali et al. (1992) who reported the value $78.20 \%$ and $78.20 \%(\mathrm{wb})$ carbohydrate in parboiled rice respectively. The content for the cooked rice $(30.47 \%)$ is significantly lower than that of parboiled rice which might be due to uptake of water during gelatinization of starch and/or cooking process. Comparing the carbohydrate content of cooked rice with that of the cooked rice (parboiled) kept at room temperature $(27.56 \%)$, in refrigerator $(26.98 \%)$ and freezer $(31.78 \%)$ for 24 hours, it is observed that significant amount of carbohydrate is fermented when the cooked rice is kept at room temperature. If the rice is kept in a refrigerator carbohydrate content is slightly fermented and there is no fermentation when it is kept at freezing temperature (at or below $\left.-9^{0} \mathrm{C}\right)$.

Total Viable Count (TVC): To assess the hygienic quality total viable count was conducted using the pre-cooled (under fan) cooked rice (parboiled) kept at room temperature, in refrigerator $\left(5-7^{\circ} \mathrm{C}\right)$ and freezer $\left(-9^{\circ} \mathrm{C}\right)$ for 24 hours, and counted load is shown in Table 3.

Table 3. Total viable load found in the cooked rice kept under various storage conditions

\begin{tabular}{|l|c|c|c|}
\hline \multirow{2}{*}{ Storage condition and duration } & \multicolumn{3}{|c|}{ Counted bacterial load } \\
\cline { 2 - 4 } & $\begin{array}{c}\text { After } 24 \text { hours } \\
\text { of incubation }\end{array}$ & $\begin{array}{c}\text { After } 48 \text { hours } \\
\text { of incubation }\end{array}$ & $\begin{array}{c}\text { After } 72 \text { hours } \\
\text { of incubation }\end{array}$ \\
\hline Stored at RT for $24 \mathrm{hr}$ & $2.7 \times 10^{3} \mathrm{cfu} / \mathrm{g}$ & $4.2 \times 10^{4} \mathrm{cfu} / \mathrm{g}$ & $9.0 \times 10^{6} \mathrm{cfu} / \mathrm{g}$ \\
\hline Refrigerated for $24 \mathrm{hr}$ & No colony found & No colony found & No colony found \\
\hline Refrigerated for $48 \mathrm{hr}$ & No colony found & $6.9 \times 10^{5} \mathrm{cfu} / \mathrm{g}$ & Uncountable colony found \\
\hline Frozen for $24 \mathrm{hr}$ & No colony found & No colony found & No colony found \\
\hline Frozen for $48 \mathrm{hr}$ & No colony found & No colony found & No colony found \\
\hline
\end{tabular}

Table 3 shows that the bacterial load counted in the cooked rice kept at room temperature $\left(30 \pm 2^{\circ} \mathrm{C}\right)$ was about $4.2 \times 10^{4} \mathrm{cfu} / \mathrm{g}$ by 48 hours of incubation, and no colony was found in the rice kept in a refrigerator $\left(5-7^{\circ} \mathrm{C}\right)$ and freezer $\left(-9^{0} \mathrm{C}\right)$ by 72 hours of incubation. Again the cooked rice was kept for another 24 hours in the refrigerator and freezer and examined for the viable count and observed $6.9 \times 10^{5} \mathrm{cfu} / \mathrm{g}$ during 48 hours of incubation of the refrigerated rice and no viable load was found for frozen rice. According to FAO/WHO expert consultation of microbiological specifications (CAC/RCP 15,1976$)$ maximum $5 \times 10^{4}$ mesophilic aerobic 
bacteria are safe for human consumption and the values at or above $10^{6}$ are unacceptable (Frazier, 1995). However, from the result as shown in Table 3, it can be concluded that to ensure maximum hygienic quality the cooked rice should be kept for a maximum period of 20 hours at room temperature and 48 hours in a refrigerator before reheating and consumption.

Sensory Evaluation of Reheated Rice (parboiled): To evaluate the sensory attributes such as colour, taste, texture and overall acceptability only five samples of the cooked rice (parboiled) such as $S_{1}$ (cooked and cooled to room temperature), $S_{2}$ (refrigerated for 20 hours and reheated), $S_{3}$ (frozen for 20 hours reheated), $S_{4}$ (refrigerated not reheated) and $S_{5}$ (frozen not reheated) were selected and served to panelists who were asked to evaluate them on a 1-9 point hedonic scale in which 1 is 'dislike extremely' while 9 is 'like extremely'. Hedonic Rating test was conducted on each one (Ranganna, 1991) and the mean scores obtained by various samples for different sensory attributes are presented in Table 4 .

Table 4. Mean scores obtained by various attributes of the cooked rice

\begin{tabular}{|l|c|c|c|c|}
\hline \multirow{2}{*}{ Types of samples } & \multicolumn{4}{|c|}{ Sensory attributes } \\
\cline { 2 - 5 } & Colour & Taste & Texture & Overall acceptability $^{\text {Tyyy }}$ \\
\cline { 2 - 5 } Sample-S & $7.92^{\mathrm{a}}$ & $8.46^{\mathrm{a}}$ & $7.54^{\mathrm{a}}$ & $7.92^{\mathrm{a}}$ \\
\hline Sample-S $_{2}$ & $7.92^{\mathrm{a}}$ & $8.23^{\mathrm{a}}$ & $7.46^{\mathrm{a}}$ & $7.85^{\mathrm{a}}$ \\
\hline Sample-S $_{3}$ & $7.78^{\mathrm{ab}}$ & $6.92^{\mathrm{b}}$ & $6.08^{\mathrm{bc}}$ & $6.85^{\mathrm{b}}$ \\
\hline Sample-S $_{4}$ & $7.31^{\mathrm{ab}}$ & $5.23^{\mathrm{c}}$ & $6.77^{\mathrm{b}}$ & $6.85^{\mathrm{b}}$ \\
\hline Sample-S & $6.85^{\mathrm{b}}$ & $5.15^{\mathrm{c}}$ & $4.62^{\mathrm{c}}$ & $4.92^{\mathrm{c}}$ \\
\hline L.S.D.(P<0.05) & 0.6725 & 0.8435 & 0.2627 & 0.7010 \\
\hline
\end{tabular}

Means with same superscript within a column are not significantly different at $\mathrm{P}<0.05$

$\mathrm{S}_{1}=$ Cooked and cooled to room temperature

$\mathrm{S}_{2}=$ Refrigerated and reheated

$\mathrm{S}_{3}=$ Frozen and reheated

$\mathrm{S}_{4}=$ Refrigerated not reheated

$\mathrm{S}_{5}=$ Frozen not reheated

Table 4 shows that sample- $S_{1}(7.92)$, sample- $S_{2}(7.92)$, sample- $S_{3}(7.78)$ and sample- $S_{4}$ (7.31) were equally acceptable and the first two samples secured the highest scores in terms of colour preference while sample- $S_{5}$ secured the lowest score (6.85). Among these the first three samples are ranked as 'like very much' while sample- $S_{4}$ (7.31) and sample- $S_{5}(6.85)$ can be ranked as 'like moderately'.

Among the five samples it is found that sample- $S_{1}$ received the highest taste score (8.46) while sample- $S_{2}$, sample- $S_{3}$, sample- $S_{4}$ and sample- $S_{5}$ scored 8.23, 6.92, 5.23 and 5.15 respectively in terms of taste preference (Table 4 ). Thus sample- $S_{1}$ and sample- $S_{2}$ were significantly different and better than other experimental samples in terms of taste preference and can be ranked as 'like very much'. From Table 4, it is also observed that in terms of texture preference sample- $S_{1}(7.54)$ and sample- $S_{2}$ (7.46) were equally acceptable and ranked as 'like moderately' while sample- $S_{5}$ secured the lowest score (4.62) and was ranked as 'neither like nor dislike'.

In terms of overall acceptability, Table 4 shows that sample- $S_{1}$ and $S_{2}$ were equally acceptable securing the highest score (7.92 and 7.85) and were the most acceptable product among the experimental samples and ranked as 'like very much', and sample- $S_{3}$ and sample$\mathrm{S}_{4}$ secured the equal score (6.85) and ranked as 'like moderately' while sample- $\mathrm{S}_{5}$ received the lowest score (4.92) and ranked as 'neither like nor dislike' which might be due to ice crystal formation, evaporation and consequent hardness of the cooked rice (parboiled). 
The overall results and discussion show that the colour, taste and texture of 'cooked rice' and 'refrigerated and reheated rice' were significantly better than those of other experimental samples, i.e., refrigeration $\left(5-7^{\circ} \mathrm{C}\right)$ for 48 hours and then reheating by microwave oven for 1 minute does not adversely affect the colour, taste, texture and overall acceptability of the cooked rice (parboiled).

\section{Conclusion}

In order to save the cooking time and supply tasteful, hygienic and nutritive cooked rice (parboiled) instantly the parboiled rice should be cooked properly and cooled to room temperature as quickly as possible by passing air spreading in a reasonable thick layer (5-7 $\mathrm{cm})$. To protect from microbial contamination the cooled rice should be transferred immediately into a refrigerator and kept for a maximum period of 48 hours. To ensure the original taste of cooked rice the refrigerated rice should be reheated by microwave oven for 1 minute before serving to the consumer. The study would be advantageous for hotels, restaurants, cafeteria or institutional (hospital) supply of cooked rice as it (1) tastes similar to the cooked rice, (2) requires less time to re-process/reheat, (3) will save much time of today's busy lives and (4) can be served instantly.

\section{References}

Ali, M.K., Malek, M.A. and Jahan, K. 1992. Nutrition of local foods. Institute of Food Science and Nutrition, Dhaka University.

Chakravarty, I. and Canet, C. 1996. Street food in Calcutta. Food Nutrition and Agriculture. 17 (18): 30-37.

FAO (Food and Agriculture Organization). 1984. Food balance sheet, 1979-81. average. Rome, FAO.

Frazier, W.C. and Westhoff, D.C. 1995. Food Microbiology. $4^{\text {th }}$ ed. and $28^{\text {th }}$ reprint 2007. Tata McGraw-Hill Pub. Co. Ltd. New Delhi. P- 54, 508.

Gopalan, C., Rama Sastri, B.V. and Bala Subramaniyan, S.C. 1980. Nutritive value of Indian foods. National Institute of Nutrition, Hyderabad, India.

Grist, D.H. 1965. Rice. Longmans, Green and Co. Ltd. London

Heldman, D.R. 1977. Food Process Engineering. AVI Pub. Co. Inc. Westport. Connecticut. USA.

Heldman, D.R. and Lund, D.B. 1992. Handbook of Food Engineering. Marcel Dekkar, Inc.

Houston, D.F. and Kohler, G.O. 1970. National Academy of Science, Washington DC, USA. P- 65.

Hubbert, W.T., Hagstad, H.V.H. and Hughes, K.L. 1996. Food Safety and Quality Assurance : Food of Animals Origin $\left(2^{\text {nd }}\right.$ ed. $)$. lowa State University, Press, Ames, lowa.

IRRI (International Rice Research Institute). 1989. International Rice Research Institute toward 2000 and beyond, Manila, Philippines. pp. 66.

Islam,M.R., Kabir, G.M.A. and Haque, M.M. 2002. Higher Secondary Chemistry, Part-II, Ashrafia Boighar, Dhaka. pp. 512-516.

Juliano, B.O. 1972. Physiocochemical properties of starch and protein and their relation to grain quality and nutritional value of rice. Int: Rice breeding. IRRI, Los Banos, Philippines. pp. 389-405.

Kik, M.C. and Williams, R.R. 1945. Nutritional improvement of white rice. Bull. 112, National Research Council, National Academy of Sciences, Washinton D.C.USA.

Kundu, M. 2006. Studies on the Processing of Instant Rice. MS Thesis. Food Thechnology. Dept. Food Thech. Rural Ind., Bangladesh Agricultura University, Mymensingh. 
McCall, E.R., Hoff Pauir, C.L. and Skau, D.B. 1951. The chemical composition of rice. A literature review. US Dept. Agr. Bur. Agr. Ind. Chem. Mimeo Cire. AIC-312, p 49.

McCane and Widdowson 1995. The Composition of Foods. The Royal Society of Chemistry and Ministry of Agriculture, Fisheries and Food. Good Fellow and Egan Phototype Setting Ltd. Cambridge, U.K.

Pearson, D. 1976. The Dictionary of Nutrition and Food Technology. $5^{\text {th }}$ Edn. Butterworth Publ. London.

Platt, B.S. 1939. Nutrition in the colonical Empire. $1^{\text {st }}$ Report. Pt. 1. pp. 60-61.

Ranganna, S. 1991. Handbook of Analysis of Quality Control for Fruit and Vegetable Products. $2^{\text {nd }}$ ed. Tata McGrawHill Pub. Co. Ltd. New Delhi. pp.3-27.

Rees, J.M. 1993. The risk factors in food chain with proper storage conditon. Journal of Alolescent health. 13 (5): 389-391.

Simmonds, D.H. 1980. Wheat and wheat quality in Australia. Bread Research Institute of Australia. Consumer Information, P.O. Box-7, North Ryde 2113.

Watt, B.K. and Merril, A.L. 1963. Composition of Foods, Raw, Processed, Prepared, US. Dep. Agric. Res. Serv. Agric. Handbook. 8. 